\title{
Socio-Demographic and Maternal Determinants of Birth Preparedness among Pregnant Women Seeking Skilled Birth Services at a Rural General Hospital, Mid Western Uganda
}

\author{
Munguiko Clement1*, Masereka Enos Mirembe1, Twesigye Deus', Bahizi Archbald² \\ ${ }^{1}$ Department of Nursing and Midwifery, Mountains of the Moon University, Fort Portal, Uganda \\ ${ }^{2}$ Uganda Blood Transfusion Services, Ministry of Health, Kampala, Uganda \\ Email: *cclementmunguiko@yahoo.com,mirembeenos@gmail.com,twesideus039@gmail.com,bahiziarchbald@gmail.com
}

How to cite this paper: Clement, M., Mirembe, M.E., Deus, T. and Archbald, B. (2019) Socio-Demographic and Maternal Determinants of Birth Preparedness among Pregnant Women Seeking Skilled Birth Services at a Rural General Hospital, Mid Western Uganda. Open Journal of Nursing, 9, 68-77.

https://doi.org/10.4236/ojn.2019.91007

Received: November 20, 2018

Accepted: January 21, 2019

Published: January 24, 2019

Copyright $\odot 2019$ by author(s) and Scientific Research Publishing Inc. This work is licensed under the Creative Commons Attribution International License (CC BY 4.0).

http://creativecommons.org/licenses/by/4.0/

\section{Abstract}

Background: Although the practice of preparing for childbirth among pregnant women is associated with $24.0 \%$ and $53.0 \%$ reduction in neonatal and maternal mortality respectively in low income countries, it remains inadequately practiced in Uganda. This study sought to assess socio-demographic and maternal determinants of birth preparedness among pregnant women at one of the rural hospitals in Uganda. Methods: This was a descriptive cross sectional study conducted among 332 pregnant women in first stage of normal labour between April and May 2017 at Kagadi hospital, mid western Uganda. In order to understand socio-demographic and maternal determinants of birth preparedness, we considered overall level of birth preparedness as our dependent variable and determined it using five elements. Data were collected using a researcher administered questionnaire. We used descriptive statistics to understand characteristics of respondents and multivariable logistic regression model to determine factors associated with birth preparedness. Results: Only 94 (28.3\%) of the 332 pregnant women who were included in the study were prepared for childbirth. We found that male partners having secondary level of education (aOR 1.86, CI 1.107 - 3.243, p 0.02), discussing birth plan with spouse (aOR 1.97, CI 1.06 - 3.490, p 0.03), monthly income of at least eighty three dollars (aOR 2.98, CI 1.847 - 5.981, p 0.002), being escorted by the spouse during ANC visit (aOR 1.73, CI $1.010-2.964, \mathrm{p}$ 0.04), intention to conceive (aOR 1.99, CI 1.087 - 3.65, p 0.026) and being health educated about birth preparedness during antenatal visit (aOR 1.90, CI 1.006 - 3.59, p 0.048) were associated with birth preparedness. Conclusion and Recommendations: We observed that the level of birth preparedness 
among respondents was associated with many socio-demographic and maternal factors. To scale up birth preparedness in rural settings, we recommend improving household financial income, reducing contraceptive unmet needs, male involvement and health education services to couples during antenatal visits.

\section{Keywords}

Magnitude, Birth Preparedness, Rural, Skilled Birth Services

\section{Back Ground}

Sub-Saharan Africa which accounted alone for 62 percent of the global maternal mortality in the year 2013 is still the riskiest region in the world for a pregnant woman to die of pregnancy or pregnancy related complications [1]. Whereas maternal mortality still remains a major challenge in Sub-Saharan Africa, some countries in the same region are still worse than others [2]. In this case, Uganda only accounts for 2 percent of annual global maternal mortality [3].

Birth Preparedness (BP) is an integral component of focused antenatal care which involves planning for normal birth and anticipating the actions needed in case of an emergency [4]. BP includes identification by the pregnant woman of the following elements before on set of labour or complications; money savings to meet childbirth related costs such as transport fee, identifying a birth companion and home caretaker and booking means of transport to the health facility [5].

Since it is not possible to precisely predict which pregnant women will experience life threatening obstetric complications, encouraging all pregnant women to prepare to access skilled birth services without delay has been identified as one of the most important intervention in safe motherhood [6]. Findings from one of the studies reveal that BP practice is associated with 24 percent significant reduction of neonatal mortality risk and 53 percent reduction in maternal mortality risk [7].

Although birth preparedness has been proven as one of the strategies to improve pregnancy and delivery outcome, its practice is still very difficult to achieve especially in rural areas and in low income countries where many people still live on less than a dollar per day [8].

In East Africa, the magnitude of birth preparedness seems not to greatly differ from other low income countries in the same continent. A study in Kenya found that the magnitude of birth preparedness was as low as 15 percent [9]. In south western Uganda, another study concluded that only 35 percent of the pregnant women who sought skilled birth services at rural health facilities were prepared for birth [10] [11] and similarly, only 25 percent in eastern Uganda were prepared [12]. 
This study aimed at establishing the level of BP and its socio-demographic and maternal determinants among pregnant women in one of the rural hospitals in western Uganda.

\section{Methodology}

\subsection{Study Design, Population and Site}

This was a cross sectional descriptive study. Data on the level of BP and its socio-demographic and maternal determinants was collected at once. The study was carried out in maternity ward of Kagadi hospital, a rural general hospital in western Uganda between 7th April 2017 and 20th May 2017 and included 332 pregnant women who were in first stage of normal labour. Pregnant women who had strong and more frequent uterine contractions were excluded from the study to avoid information bias.

\subsection{Sample Size Determination and Sampling Technique}

Sample size of respondents was determined using Kish and Frankel formula for a single population proportion:

$$
n=\frac{z^{2} p q}{e^{2}}
$$

The value from standard normal distribution $(Z)$ at $95 \%$ Confidence Interval (CI) was set at 1.96 , for the proportion $(p)$, we considered the proportion of 0.35 for pregnant women who were found to be prepared for birth in south western Uganda. The margin of error (e) was set at 5\% (0.05) and the value of $q$ was calculated by subtracting the value of $p$ from constant value of 1 . Respondents were consecutively recruited into the study as they came to maternity ward for skilled birth attendance services.

\subsection{Data Collection and Analysis}

Pregnant women who had come to deliver at maternity ward were identified using the level of cervical dilatation recorded on their clinical charts to ascertain that they were in first stage of labour. We used clinical notes to exclude pregnant women who had strong and more frequent uterine contractions. We collected data using a pretested structured questionnaire. The questionnaire was both in English and in Runyoro Rutooro dialect, a local language commonly spoken in the area. Using language of choice by respondents, a researcher asked questions as they appeared in the questionnaire and recorded responses in the same questionnaire accordingly. To determine socio-demographic and maternal determinants of BP, we considered level of BP among respondents as our dependent variable and considered the following five elements to establish it; having money saved by the woman (Uganda shillings equivalent to $\geq 28$ USD), booking someone to take care of home while the woman is at health facility for delivery, earlier identification of a birth companion, having birth materials at the bedside and 
earlier booking means of transport to the hospital. Respondents who scored at least three of the five elements were considered prepared for childbirth. Data was analyzed using SPSS version 23. We used multivariable logistic regression to determine socio-demographic and maternal factors associated with BP and only variables with $\mathrm{p} \leq 0.2$ from bivariable models were included. In addition, factors thought to be plausible were added to multivariable logistic regression model. Factors which were significant at multivariate logistic regression were considered true determinants of birth preparedness in rural mid western Uganda.

\subsection{Ethical Considerations}

Approval of the protocol was obtained from Institutional Review Board (IRB) at the College of Health Sciences (CHS), Makerere University, Uganda. We also obtained written consent from all pregnant women who met inclusion criteria before they were enrolled into the study. In order to ensure privacy, data was collected from admission room. This room had one chair for service provider, examination bed and one chair for a client. The room accommodated one client at a time. Alternatively, we used a working table in labour room. This table also only accommodated one client at a time.

\section{Results}

\subsection{Socio-Demographic and Maternal Characteristics of Pregnant Women at a Rural General Hospital in Mid Western Uganda}

A total of 332 pregnant women with mean age of 23.6 participated in the study. Most of the pregnant women, 215 (64.8\%) were not married and more than half of them, $233(70.2 \%)$ had discussed birth preparedness plan with their spouses before onset of labour. Two thirds of the pregnant women, 219 (66\%) intended to conceive and only 145 (43.8\%) had completed at least four or more ANC visits. About half of the pregnant women, 184 (55.3\%) were not escorted by their spouses but reviewed birth plan together with midwives during ANC. A significant proportion of women (69.7\%) reported that they were health educated about BP during ANC visits. Only 94 (28.3\%) respondents scored at least three of the five elements and were considered as prepared for birth. See Table 1 and Table 2.

\subsection{Socio-Demographic Determinants of Birth Preparedness at a Rural General Hospital in Mid Western Uganda}

We found that monthly income of women of Uganda shillings equivalent to eighty three US dollars or more (aOR 2.98, CI 1.847 - 5.981, p 0.002), education of spouse of at least secondary level (aOR 1.86, CI 1.107 - 3.243, p 0.020), monthly income of spouse of Uganda shillings equivalent to eighty three US dollars or more (aOR 2.37, CI 1.286 - 4.364, p 0.006) and discussing birth plan with spouse (aOR 1.97, CI 1.06 - 3.490, p 0.03) were socio-demographic determinants of birth preparedness. From bivariable analysis models, we found that: 
Table 1. Socio-demographic characteristics of participants $(n=332)$.

\begin{tabular}{|c|c|c|}
\hline Demographics & Frequency (mean) & Percentage (\%) \\
\hline \multicolumn{3}{|l|}{ Age } \\
\hline$\leq 19$ years & $102(23.56)$ & 30.7 \\
\hline$>19$ years & 230 & 69.3 \\
\hline \multicolumn{3}{|l|}{ Occupation } \\
\hline Farming & 139 & 41.9 \\
\hline House wife & 100 & 30.1 \\
\hline Others & 93 & 28 \\
\hline \multicolumn{3}{|l|}{ Residence } \\
\hline Urban & 111 & 33.4 \\
\hline Rural & 221 & 66.6 \\
\hline \multicolumn{3}{|c|}{ Number of people per house hold } \\
\hline$\leq 3$ & 202 & 60.8 \\
\hline$>3$ & 130 & 39.2 \\
\hline \multicolumn{3}{|l|}{ Marital status } \\
\hline Married & 117 & 35.2 \\
\hline Not married & 215 & 64.8 \\
\hline \multicolumn{3}{|l|}{ Level of education } \\
\hline None & 37 & 11.1 \\
\hline Primary & 188 & 56.6 \\
\hline Secondary & 97 & 29.2 \\
\hline Tertiary & 10 & 3.0 \\
\hline \multicolumn{3}{|l|}{ Level of education of spouse } \\
\hline None & 12 & 3.6 \\
\hline Primary & 154 & 46.4 \\
\hline Secondary & 140 & 42.2 \\
\hline Tertiary & 26 & 7.8 \\
\hline \multicolumn{3}{|c|}{ Distance to the nearby health facility } \\
\hline$<5 \mathrm{~km}$ & 96 & 28.9 \\
\hline$\geq 5 \mathrm{~km}$ & 236 & 71.1 \\
\hline \multicolumn{3}{|c|}{ Monthly income of respondent (USD) } \\
\hline$<83.3$ & $236(33.2)$ & 71.0 \\
\hline$\geq 83.3$ & 46 & 13.9 \\
\hline No earning & 50 & 15.1 \\
\hline \multicolumn{3}{|c|}{ Monthly income of spouse (USD) } \\
\hline$<83.3$ & 247 & 74.4 \\
\hline$\geq 83.3$ & 70 & 21.1 \\
\hline No earning & 15 & 4.5 \\
\hline \multicolumn{3}{|l|}{ Occupation of spouse } \\
\hline Farming & 88 & 26.5 \\
\hline Business & 149 & 44.9 \\
\hline Others & 95 & 28.6 \\
\hline \multicolumn{3}{|c|}{ Discussion with spouse about BP } \\
\hline Yes & 233 & 70.2 \\
\hline No & 99 & 29.8 \\
\hline
\end{tabular}


Table 2. Maternal characteristics and level of birth preparedness of participants $(n=332)$.

\begin{tabular}{|c|c|c|}
\hline Maternal characteristics & Frequency & Percentage (\%) \\
\hline \multicolumn{3}{|l|}{ Gravidity } \\
\hline 1 & 118 & 35.5 \\
\hline$\geq 2$ & 214 & 64.5 \\
\hline \multicolumn{3}{|l|}{ Had poor obstetric history } \\
\hline Yes & 198 & 59.6 \\
\hline No & 134 & 40.4 \\
\hline \multicolumn{3}{|l|}{ Health status during pregnancy } \\
\hline Good & 197 & 59.3 \\
\hline Bad & 135 & 40.7 \\
\hline \multicolumn{3}{|l|}{ Intention to conceive } \\
\hline Yes & 219 & 66.0 \\
\hline No & 113 & 34.0 \\
\hline \multicolumn{3}{|l|}{ Attended ANC } \\
\hline Yes & 328 & 98.8 \\
\hline No & 4.0 & 1.2 \\
\hline \multicolumn{3}{|l|}{ Timing of ANC first attendance } \\
\hline$<3$ months & 59 & 17.7 \\
\hline 3 - 6 months & 234 & 70.3 \\
\hline 6 - 9 months & 37 & 11.1 \\
\hline \multicolumn{3}{|l|}{ Number of ANC attendances } \\
\hline$<4$ times & 184 & 55.3 \\
\hline$\geq 4$ times & 146 & 43.8 \\
\hline \multicolumn{3}{|l|}{ Escorted by spouse during ANC } \\
\hline Yes & 146 & 43.8 \\
\hline No & 184 & 55.3 \\
\hline \multicolumn{3}{|l|}{ Level of birth preparedness } \\
\hline Prepared & 94 & 28.3 \\
\hline Not prepared & 238 & 71.7 \\
\hline
\end{tabular}

Age (OR 0.821, CI 0.48 - 1.35, p 0.48), tribe (OR 0.90, CI 0.55 - 149, p 0.99), place of residence (OR 0.86 , CI 0.52 - 1.45, p 0.67) and marital status (OR 1.19, CI 0.74 - 1.93, p 0.54) were not significant socio-demographic factors associated with BP. See Table 3.

\subsection{Maternal Determinants of Birth Preparedness at a Rural General Hospital in Mid Western Uganda}

Our study revealed that intention to conceive (aOR 1.99, CI $1.087-3.65, \mathrm{p}$ 0.026), health education about BP during antenatal care (aOR 1.90, CI 1.006 $3.59, \mathrm{p} 0.048$ ) and being escorted by the spouse during antenatal care visit (aOR 1.73 , CI 1.010 - 2.964, p 0.04) were maternal determinants of birth preparedness. 
Table 3. Socio-demographic and maternal determinants of birth preparedness at a rural hospital in mid western Uganda.

\begin{tabular}{|c|c|c|c|}
\hline Variable & Adjusted OR & $p$ value & $95 \% \mathrm{CI}$ \\
\hline \multicolumn{4}{|l|}{ Socio-demographic determinants } \\
\hline \multicolumn{4}{|l|}{ Monthly income level (USD) } \\
\hline$\geq 83.3$ & 2.98 & $0.002^{*}$ & $1.487-5.981$ \\
\hline$<83.3$ & 1.00 & & \\
\hline \multicolumn{4}{|l|}{ Education level } \\
\hline Secondary or beyond & 1.04 & 0.889 & $0.605-1.784$ \\
\hline Below secondary & 1.00 & & \\
\hline \multicolumn{4}{|l|}{ Education level of the spouse } \\
\hline Secondary or beyond & 1.86 & $0.020^{*}$ & $1.107-3.243$ \\
\hline Below secondary & 1.00 & & \\
\hline \multicolumn{4}{|l|}{ Income level of the spouse (USD) } \\
\hline$\geq 83.3$ & 2.37 & $0.006^{*}$ & $1.286-4.364$ \\
\hline$<83.3$ & 1.00 & & \\
\hline \multicolumn{4}{|l|}{ Discussed about BP with spouse } \\
\hline Yes & 1.97 & $0.030^{*}$ & $1.064-3.490$ \\
\hline No & 1.00 & & \\
\hline \multicolumn{4}{|l|}{ Maternal determinants } \\
\hline \multicolumn{4}{|l|}{ Intention to conceive } \\
\hline Yes & 1.99 & $0.026^{*}$ & $1.087-3.650$ \\
\hline No & 1.00 & & \\
\hline \multicolumn{4}{|l|}{ Reviewed birth plan with midwife } \\
\hline Yes & 1.71 & 0.057 & $0.983-2.978$ \\
\hline No & 1.00 & & \\
\hline \multicolumn{4}{|c|}{ Health educated on birth preparedness during ANC } \\
\hline Yes & 1.90 & $0.048^{*}$ & $1.006-3.59$ \\
\hline No & 1.00 & & \\
\hline \multicolumn{4}{|l|}{ Escorted by spouse during ANC } \\
\hline Yes & 1.73 & $0.040^{*}$ & $1.010-2.964$ \\
\hline No & 1.00 & & \\
\hline \multicolumn{4}{|l|}{ Health status during pregnancy } \\
\hline Good & 1.35 & 0.268 & $0.795-2.284$ \\
\hline Bad & 1.00 & & \\
\hline
\end{tabular}

${ }^{*}$ Means statistically significant at $\mathrm{p}$ value $<0.05$.

From bivariable analysis models, our study revealed that; gravidity (OR 0.79, CI 0.48 - 1.32, p 0.45), obstetric history (OR 0.73, CI 0.43 - 1.19, p 0.217) and number of ANC visits (OR 0.64, CI 0.39 - 1.03, p 0.85) of the respondents were not significant predictors of their preparedness for child birth. See Table 3.

\section{Discussion}

Our study found that pregnant women who earned Uganda shillings equivalent to eighty three US dollars per month were about 3 times more likely to prepare for child birth than those who earned less. Similarly, pregnant women whose 
spouses earned the same amount of money or more were also about 2.4 times more likely to prepare for child birth than pregnant women whose spouses earned less. Further analyzes indicated that the level of BP increased with the increase in financial income of pregnant women and their spouses. This was possibly because most of the elements of BP we considered, required one to have some money to meet their demand and most likely those who had some money were able to do so. Findings from our study concurred with the findings from the study in south western Uganda where husbands who had reasonably good and regular income were more likely to support their spouses to have the items required for childbirth [13]. The level of education of the spouse also influenced child birth preparedness. A pregnant woman whose spouse had completed secondary level of education or beyond was 1.8 times more likely to prepare for child birth than one whose spouse had not. This finding was not surprising. In one of the research studies, it was found that educated spouses are more likely to understand the importance of preparing for child birth than those who are not educated [14]. Drawing and regularly discussing birth plan as a couple was another significant socio-demographic determinant of birth preparedness. Our study found that a pregnant woman who drew and regularly discussed birth plan with her spouse was about 2.0 times more likely to prepare for child birth than the other who did not involve her spouse in child birth planning. This is probably because the practice brings the male partner on board and encourages him to support his partner. In addition, since it is a cultural practice in most of the communities in Africa that a man is a chief executive of the family and for that matter, he controls family income and expenditure, involving him in child birth planning brings on board the money which is much needed to procure all elements of BP.

Regarding maternal factors, our study found that intention to conceive was one of the significant determinants of birth preparedness. A respondent who had intended to get pregnant was about 2 times more likely to prepare for child birth than one who had not intended to conceive. This could be due to the fact that the intention to become pregnant is most likely an agreed decision between the woman and her husband. This also means that this baby is desired and preparation will be done early so that nothing prevents the couple from realizing their dream of having a healthy baby. Similarly, pregnant women who were escorted by their spouses during antenatal visits were about 1.7 times more likely to prepare for child birth compared to those who were not escorted. This is possibly due to the fact that men's involvement in antenatal care increases the likelihood that men will be taught about birth preparedness which increases the likelihood that men will support their wives to do so. Our study also revealed that respondents who were health educated about birth preparedness during ANC visit were 1.9 times more likely to prepare for skilled birth than those who were not. This is because health education increases the woman's insight on the relevancy of being prepared before the expected date of childbirth [15]. 


\section{Conclusion and Recommendations}

Birth preparedness practice among pregnant women was found to be very low. We found that a number of socio-demographic and maternal factors greatly influenced BP practice of pregnant women. These predictors included the level of income of both the pregnant woman and her partner, the level of education of the male partner, male involvement in BP planning and ANC as well as intention to conceive. In order to scale up the magnitude of birth preparedness, we recommend that children should stay in school and complete all cycles of formal education, couples should improve their household financial income and that male partners should be involved in BP planning and ANC attendance. Providers of contraceptive methods should aim at meeting contraceptive needs of clients so as to improve on intentions to conceive. In addition, health workers need to regularly provide health education sessions to couples on BP during antenatal visits.

\section{Acknowledgements}

We acknowledge the contribution of pregnant women who volunteered as respondents in this study. This study would have not been a success if they did not offer their time, patience and genuine responses to this study. Special gratitude goes to Institutional Review Board (IRB) at the College of Health Sciences (CHS), Makerere University for providing ethical clearance of our study. We also thank the management staff of Kagadi hospital for granting us permission to conduct this study in the hospital they superintend. Without the support of all the mentioned and those not mentioned here, this study would not have been successful.

\section{Conflicts of Interest}

Submitting author and coauthors of this article do not have any conflict of interest whatsoever.

\section{Data Availability}

Previously published data were used to support this study and are cited at appropriate places in the text.

\section{Funding}

There was no funding agency for this study. This study was conducted as part of the employment performance output of authors.

\section{References}

[1] Iaccino, L. (2014) Child Sexual Abuse: Top 5 Countries with the Highest Rates. International Business Times, 16, 12.

[2] Say, L., et al. (2014) Global Causes of Maternal Death: A WHO Systematic Analysis. The Lancet Global Health, 2, e323-e333. 
https://doi.org/10.1016/S2214-109X(14)70227-X

[3] Kent, A. (2010) Global Maternal Mortality Rates. Reviews in Obstetrics and Gynecology, 3, 141.

[4] August, F., Pembe, A.B., Mpembeni, R., Axemo, P. and Darj, E. (2015) Men's Knowledge of Obstetric Danger Signs, Birth Preparedness and Complication Readiness in Rural Tanzania. PLoS ONE, 10, e0125978. https://doi.org/10.1371/journal.pone.0125978

[5] McPherson, R.A., Khadka, N., Moore, J.M. and Sharma, M. (2006) Are Birth-Preparedness Programmes Effective? Results from a Field Trial in Siraha District, Nepal. Journal of Health, Population and Nutrition, 24, 479-488.

[6] Mukhopadhyay, D.K., Mukhopadhyay, S., Bhattacharjee, S., Nayak, S., Biswas, A. K. and Biswas, A.B. (2013) Status of Birth Preparedness and Complication Readiness in Uttar Dinajpur District, West Bengal. Indian Journal of Public Health, 57, 147-153. https://doi.org/10.4103/0019-557X.119827

[7] Soubeiga, D., Gauvin, L., Hatem, M.A. and Johri, M. (2014) Birth Preparedness and Complication Readiness (BPCR) Interventions to Reduce Maternal and Neonatal Mortality in Developing Countries: Systematic Review and Meta-Analysis. BMC Pregnancy and Childbirth, 14, 129. https://doi.org/10.1186/1471-2393-14-129

[8] Brazier, E., Fiorentino, R., Barry, S., Kasse, Y. and Millimono, S. (2014) Rethinking How to Promote Maternity Care-Seeking: Factors Associated with Institutional Delivery in Guinea. Health Care for Women International, 35, 878-895. https://doi.org/10.1080/07399332.2014.916293

[9] Gitonga, E., Keraka, M. and Mwaniki, P. (2015) Birth Preparedness among Women in Tharaka Nithi County, Kenya. African Journal of Midwifery and Women's Health, 9, 153-157. https://doi.org/10.12968/ajmw.2015.9.4.153

[10] Kabakyenga, J.K., Östergren, P.-O., Turyakira, E. and Pettersson, K.O. (2012) Influence of Birth Preparedness, Decision-Making on Location of Birth and Assistance by Skilled Birth Attendants among Women in South-Western Uganda. PLoS ONE, 7, e35747. https://doi.org/10.1371/journal.pone.0035747

[11] Kabakyenga, J.K., Östergren, P.-O., Turyakira, E. and Pettersson, K.O. (2011) Knowledge of Obstetric Danger Signs and Birth Preparedness Practices among Women in Rural Uganda. Reproductive Health, 8, 33. https://doi.org/10.1186/1742-4755-8-33

[12] Timša, L., Marrone, G., Ekirapa, E. and Waiswa, P. (2015) Strategies for Helping Families Prepare for Birth: Experiences from Eastern Central Uganda. Global Health Action, 8, Article ID: 23969. https://doi.org/10.3402/gha.v8.23969

[13] Kakaire, O., Kaye, D.K. and Osinde, M.O. (2011) Male Involvement in Birth Preparedness and Complication Readiness for Emergency Obstetric Referrals in Rural Uganda. Reproductive Health, 8, 12. https://doi.org/10.1186/1742-4755-8-12

[14] Bintabara, D., Mohamed, M.A., Mghamba, J., Wasswa, P. and Mpembeni, R.N. (2015) Birth Preparedness and Complication Readiness among Recently Delivered Women in Chamwino District, Central Tanzania: A Cross Sectional Study. Reproductive Health, 12, 44. https://doi.org/10.1186/s12978-015-0041-8

[15] Hiluf, M. and Fantahun, M. (2008) Birth Preparedness and Complication Readiness among Women in Adigrat Town, North Ethiopia. Ethiopian Journal of Health Development, 22, 14-20. https://doi.org/10.4314/ejhd.v22i1.10057 